\title{
Análise da rentabilidade em avicultura: uma avaliação do setor de produção avícola no IFPB-Campus
} Sousa

\author{
Mateus Gonçalves Silva1*, Vanclea Teles da Silva Sousa, Daiane Carvalho do Nascimento, Fábio Queiroga \\ Pordeus
}

\begin{abstract}
RESUMO: A avicultura é uma atividade agropecuária de grande importância econômica no Brasil e em outros países. Apresenta dois segmentos diferentes: o de corte para produção de carne e o de postura para produção de ovos. A análise da rentabilidade no setor agropecuário de produção é imprescindível para melhor administração do empreendimento, controlando os gastos e analisando a rentabilidade. No IFPB-Campus Sousa, onde funcionam cursos técnicos e superiores da área de ciências agrárias, o setor de avicultura tem a função de subsídio para aulas práticas, e parte da produção é destinado ao refeitório e agroindústria, sendo consumidos pelos próprios alunos. O presente trabalho teve por objetivo analisar a produção de ovos no setor de criação de galinhas de postura do IFPB, avaliando os custos de produção, a produtividade e rentabilidade. Observou-se que existem certas variações de acordo com a demanda da instituição, porém a atividade se mostrou lucrativa. As receitas cobrem os custos durante quase todos os meses, exceto quando aumenta a demanda para atender a necessidade alimentar dos alunos. A relação custo benefício para os meses de janeiro a julho apresentou-se positiva, expressando valor de $\mathrm{R} \$ 0,94$ centavos.
\end{abstract}

Palavras-chave: Agropecuária; Criação de galinhas; Custos de produção

\section{Analysis of profitability in poultry: an evaluation of the poultry production sector at the IFPB- Campus Sousa}

\begin{abstract}
Poultry farming is an agricultural activity of great economic importance in Brazil and in other countries. It presents two different segments: the cut for meat production and the posture for egg production. The analysis of the profitability in the agricultural sector of production is essential for better administration of the enterprise, controlling the expenses and analyzing the profitability. At the IFPB-Campus Sousa, where technical and higher courses in the field of agricultural science work, the poultry sector has the function of subsidizing practical classes, and part of the production is destined for the refectory and agribusiness, being consumed by the students themselves. The present work had the objective of analyzing the egg production in the poultry hatchery of the IFPB, evaluating production costs, productivity and profitability. It was observed that there are certain variations according to the demand of the institution, but the activity was profitable. Revenue covers costs for almost every month except when demand increases to meet the students' food needs. The cost benefit ratio for the months of January to July was positive, expressing a value of R \$ 0.94 cents.
\end{abstract}

Keywords: Agropecuária; Breeding of chickens; Production costs

\section{INTRODUÇÃO}

Estudos sobre custos de produção na agricultura são imprescindíveis, uma vez que através de dados reais se reflete o nível de eficiência que a atividade está sendo desenvolvida na propriedade (GIROTTO, 2008).

Hofmann et al. (1981) e Naylor \& Vernon (1973) deduzem que para os proprietários continuem produzindo, é preciso que recebam uma compensação pelo capital despendido na atividade e que ao empregar um determinado fator para produzir certo bem seu custo é o valor de sua melhor oportunidade a qual se renuncia ao empregar esse fator em outra alternativa de produção ou exploração.

A avicultura é uma atividade agropecuária de grande importância econômica no Brasil e em outros países. Apresenta dois segmentos diferentes: $\mathrm{O}$ de corte para produção de carne e o de postura para produção de ovos, que são bastante consumidos pela população. É um setor que vem se desenvolvendo e proporcionando um crescente aumento na produção de ovos no Brasil, e atrelado a outras atividades agrícolas, como plantações anuais, criação de outros tipos de animais, promove a diversificação da dieta alimentar e renda de muitos produtores rurais.

Conforme Angelo (2010) o cenário da avicultura no Brasil é bastante positivo, pois o nosso país tem grande potencial nesta atividade em razão das condições favoráveis de clima, área, mão de obra, condições de biosseguridade e capacidade empreendedora para projetos avícolas.

Albino (1998) afirma que o desenvolvimento da avicultura brasileira deve-se a uma associação entre

\footnotetext{
Recebido em 01/08/2018; Aceito para publicação em 25/02/2019

${ }^{1}$ Instituto Federal da Paraíba

*E-mail: matheus.goncalves2102@gmail.com
} 
genética, nutrição, manejo e sanidade, aliadas a facilidade com que $o$ setor adota as novas tecnologias e as técnicas de manejo para obter altos índices de produtividade.

Os custos de produção no setor de criação de galinhas tanto para corte como para postura é bastante elevado para quem vai entrar na atividade, pois requer desempenho durante todo o manejo desde a incubação dos ovos até os frangos com idade para o abate e postura. Os custos envolvem inúmeras variáveis como por exemplo: Energia elétrica, ração, água, medicamentos veterinários e uma gama de outros recursos indispensáveis na criação.

Para se obter sucesso na criação, na produção e consequentemente na lucratividade para o agricultor, é necessária uma melhoria na gestão dos custos de produção da atividade, buscando organização de todos os dados referentes aos custos para se ter uma melhor administração, sempre buscado melhorias para economizar sem prejudicar a produção. De acordo com Martins (2001) com informações da contabilidade de custos a contabilidade financeira pode-se planejar melhor o desembolso e a contabilidade gerencial pode fornecer maior controle sobre o que é produzido, tentando reduzir custos e tomar decisões mais precisas.

No IFPB-Campus Sousa, onde funcionam cursos técnicos e superiores da área de ciências agrárias, ambientais e de alimentos, (técnico em agropecuária, técnico em agroindústria, técnico em meio ambiente, superior de tecnologia em agroecologia, superior de tecnologia em alimentos e bacharelado em medicina veterinária), o setor de avicultura tem a função de subsídio para aulas práticas, e parte da produção é destinado ao refeitório e agroindústria, sendo consumidos pelos próprios alunos, o excedente é comercializado na tesouraria. A atividade não é exclusivamente para produção e obtenção de lucro, e desse modo, não é possível uma análise totalmente financeira.

Diante dos argumentos supracitados, o presente trabalho surge com o objetivo de avaliar custos de produção no setor de avicultura do IFPB-Campus Sousa, assim como também a produtividade e receitas prováveis, comentando sobre a destinação final dos ovos.

\section{MATERIAL E MÉTODOS}

A pesquisa foi realizada no Instituto Federal de Educação, Ciência e Tecnologia da Paraíba (IFPB)Campus Sousa, unidade São Gonçalo, estando localizado no Perímetro Irrigado de São Gonçalo, na zona fisiográfica do Sertão Paraibano a 220 metros de altitude, de coordenadas geográficas, latitude $6^{\circ} 45^{\text {" }} 33^{\prime \prime}$ Sul e longitude $38^{\circ} 13^{\circ} 41^{\prime \prime}$. Segundo a classificação de Köppen, o clima da região é do tipo
Bsh (quente), com temperatura média anual de $27^{\circ}$, com mínima de $22^{\circ}$ e máxima de $36^{\circ}$, os solos aluvionais, dominantes na área do perímetro irrigado, são profundos, de textura média a argilosa (NÓBREGA et al, 2018).

$\mathrm{Na}$ realização deste trabalho, utilizou-se a metodologia do "estudo de caso", a partir da coleta de dados junto ao departamento de finanças do IFPB-Campus Sousa.

O estudo de caso, de acordo com Yin (2002), ressalta algumas estratégias que são obedecidas por pesquisadores das ciências sociais em trabalhos científicos, quais sejam: a experimental, o levantamento, a análise documental desenvolvida em arquivos e o estudo de caso. Os propósitos destas estratégias podem ser de caráter exploratório, descritivo e explanatório (causal). O objetivo desse tipo de pesquisa (estudo de caso) é de proporcionar uma visão global do problema ou identificar possíveis fatores que o influenciam ou são influenciados por ele. Uma das vantagens de se trabalhar com estudos de caso é que se pode analisar uma situação concreta e não uma situação puramente hipotética. A metodologia de estudo de casos tem a premissa de buscar uma imagem mais real e completa dos fatos que caracterizam o problema observado.

Quanto a este trabalho, a obtenção de dados se deu por análise documental, de caráter exploratório junto ao responsável que coordena o setor de produção, buscando assim levantar dados mensais sobre os custos e a produção no setor de avicultura referentes ao período de janeiro à julho de 2017. Os dados referentes a custos de produção tiveram as seguintes variáveis analisadas: Ração, energia, água, medicamentos, mão de obra e manutenção do aviário. Já nos dados que envolvem a produção analisamos somente a produtividade de ovos médios por dúzia, já que o setor estava funcionando somente a parte de avicultura de postura.

\section{RESULTADOS E DISCUSSÃO}

As instalações para as galinhas encontradas no IFPB são compostas por quatro galpões, sendo dois destinados para galinhas de corte e os outros dois para galinhas poedeiras, porém, no momento em que foi realizada a pesquisa o setor estava ativo somente para galinhas poedeiras. Conta também com um funcionário, responsável pelo manejo dos galpões e das galinhas como também pela produtividade e destino dos ovos. A ração que é fornecida aos animais é comprada fora, a mistura é feita na instituição, onde o funcionário responsável pelo setor informa as quantidades de cada concentrado para assim ser feita. 
Atualmente o setor conta de um número total de 500 aves em produção de ovos, no contexto de se tratar de uma unidade acadêmica voltada para didática, os custos de produção apresentam um total de $\mathrm{R} \$ 3.825,89$ no geral envolvendo todos os animais e todos os custos operacionais variáveis e fixos da produção (tabela 1).

Tabela 1. Custos de produção no setor avícola do IFPB-Campus Sousa, para total de 500 animais, julho/2017

\begin{tabular}{|c|c|c|c|c|}
\hline \multirow{2}{*}{ Consumo } & \multirow{2}{*}{ Mês } & \multirow{2}{*}{ Valor U. (R\$) } & \multirow{2}{*}{$\begin{array}{c}\text { Quantidade x Valor U. } \\
(\mathbf{R} \$)\end{array}$} & \multirow{2}{*}{$\frac{(Q \times \text { Valor U. })}{n^{0} \text { animais }}$} \\
\hline & & & & \\
\hline Ração (kg) & 1.335 & 1,27 & $1.695,45$ & $1.695,45$ \\
\hline Energia $(\mathrm{kw})$ & 1.188 & 0,43 & 510,84 & 510,84 \\
\hline Agua $\left(\mathrm{m}^{3}\right)$ & 60 & 7,66 & 459,6 & 459,6 \\
\hline Medicamentos (R\$) & 10 & $\begin{array}{l}-- \\
\end{array}$ & 10 & 10 \\
\hline Mão de obra (R\$) & 1050 & --- & 1050 & 1050 \\
\hline \multirow[t]{2}{*}{ Manutenção do aviário (R\$) } & 100 & --- & 100 & 100 \\
\hline & & & Total & $3.825,89$ \\
\hline
\end{tabular}

*Consumo total do mês expresso em unidades de medidas para cada item; *Valor unitário expresso em reais para cada item Elaborado pelos autores

O total dos custos operacionais variáveis chega a $\mathrm{R} \$ 5,35$ por ave e um total de $\mathrm{R} \$ 2.675,00$ por 500 animais em produção. Já os custos operacionais fixos, que são aqueles gastos com mão de obra chegam a ser $\mathrm{R} \$ 2,30$ por ave e um total de $\mathrm{R} \$ 1.150,00$. Justamente o salário mímino mais os encargos sociais pagos ao terceirizado para cuidar do setor, fiscalizando, dispinibilizando ração e fazendo limpeza do local, e ainda os gastos com materiais utilizados para a manutenção do aviário, com reformas e ajustes. (tabela 2).

Tabela 2. Custos operacionais variáveis e fixos no setor avícola do IFPB-Campus Sousa, para total de 500 animais, julho/2017

\begin{tabular}{l|l|l}
\hline Custos operacionais variáveis & $\begin{array}{l}\text { Valor unitário } \\
(\mathbf{R} \$ / \mathbf{a v e})\end{array}$ & $\begin{array}{l}\text { Valor Total } \\
(\mathbf{R} \$)\end{array}$ \\
\hline Ração $(\mathrm{kg})$ & 3,39 & 1.695 \\
\hline Energia $(\mathrm{Kw})$ & 1,02 & 510 \\
\hline Água $\left(\mathrm{m}^{3}\right)$ & 0,92 & 460 \\
\hline Medicamentos & 0,02 & 10 \\
\hline Total $(\mathbf{C . O . V})$ & $\mathbf{5 , 3 5}$ & $\mathbf{2 . 6 7 5}$ \\
\hline Custos operacionais fixos & Valor unitário $(\mathbf{R}$ \$/ave $)$ & Valor total $(\mathbf{R} \$)$ \\
\hline & & \\
Mão de obra (insalubridade, inss) & 2,1 & 1.050 \\
\hline Manutenção do aviário & 0,2 & 100 \\
\hline Total $(\mathbf{C . O . F})$ & $\mathbf{2 , 3}$ & $\mathbf{1 . 1 5 0}$ \\
\hline $\begin{array}{l}\text { Custos operacionais totais da } \\
\text { produção }\end{array}$ & $\mathbf{7 , 6 5}$ & $\mathbf{3 . 8 2 5}$ \\
\hline
\end{tabular}

Elaborado pelos autores

Costa et al. (2005) em seu estudo sobre a exploração avícola de corte no Distrito Federal encontra resultados semelhantes sobre o custo operacional de produção com aproximadamente R $\$$ 6,38/ave.

$\mathrm{Na}$ composição percentual dos custos de produção operacionais totais do setor de avicultura, a ração ocupa o primeiro lugar com $44,31 \%$, seguido pelo a mão de obra que chega a $27,45 \%$, dados estes semelhantes aos encontrados por Schwartz (2017) avaliando os custos de produção em sistemas de produção de ovos nos estados de São Paulo e Paraná, que apresentaram uma média respectivamente de $43,86 \%$ e $12,73 \%$. Costa et al. (2005) pesquisando sobre a exploração avícola no Distrito Federal encontra resultados semelhantes aos desta pesquisa para medicamentos e mão de obra, com respectivamente $1,1 \%$ e $16,6 \%$, valores próximos a $0,26 \%$ e $27,45 \%$ (figura 1 ). 


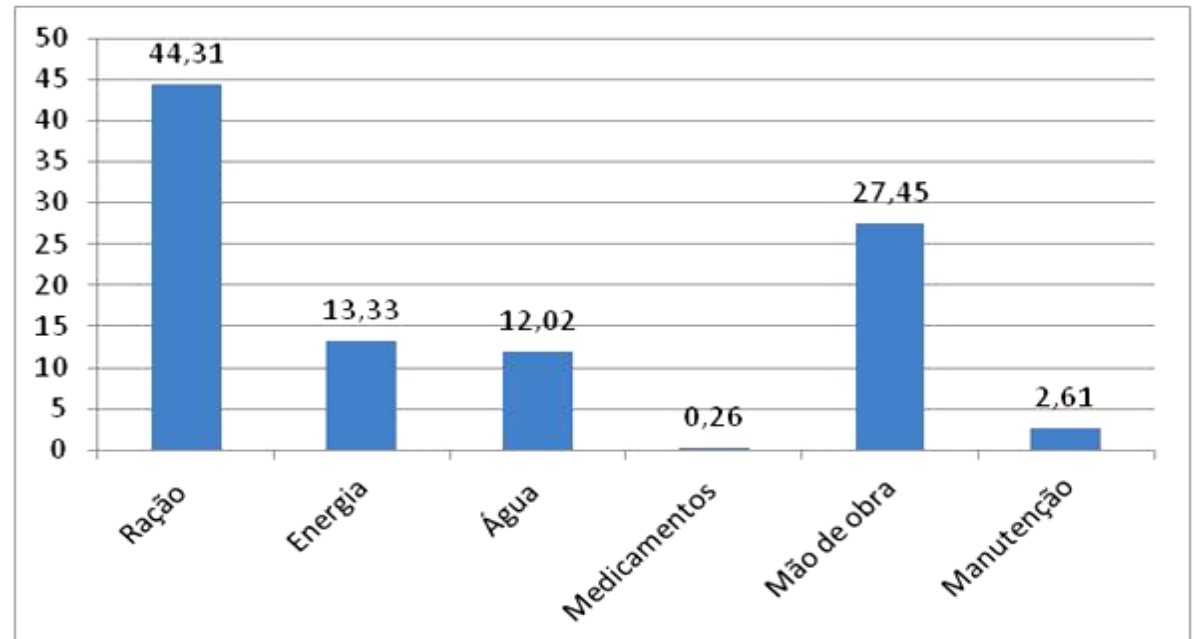

Figura 1. Composição percentual de custos operacionais de produção no setor avícola do IFPB-Campus Sousa, para total de 500 animais, julho/2017

$\mathrm{O}$ custo com medicamentos chega a ser bem baixo, uma vez que não se gasta muito com estes produtos para as aves, já que as mesmas estão sempre presas e longe de agentes patógenos. Porém é indicado fazer um correto manejo da criação afim de evitar o aumento com estes gastos, que podem crescer rapidamente quando se tem uma epidemia com doenças.

Os dados obtidos para produtividade entre os meses de janeiro a julho de 2017 foram os descritos na tabela 3 , onde produção dos 7 meses chegaram a um total de 3.162 bandejas com 30 ovos cada. Costa et al. (2005) pesquisando a produção na avicultura alternativa em Distrito Federal constata uma escala média de produção de 2.107 caixas de 360 ovos/produtor/ano.

Por se tratar de uma instituição que produz para desenvolvimento de aulas práticas pelos alunos foi explicitada a destinação final dos produtos (ovos médios) em quantidades de bandejas, para o refeitório, agroindústria ou para venda na tesouraria. A maior parte é destinado a tesouraria onde é comercializado a bandeja de ovos ao preço de $\mathrm{R} \$$ 8,00 .

Tabela 3. Produtividade mensal do setor avícola de postura do IFPB-Campus Sousa, para total de 500 animais, julho/2017

\begin{tabular}{l|c|c|c}
\hline \multirow{2}{*}{ Meses } & \multicolumn{2}{|c|}{ Consumo (Bdj) } & Venda (Bdj) \\
\cline { 2 - 4 } & Refeitório & Agroindústria & Tesouraria \\
\hline Janeiro & 0 & 0 & 485 \\
\hline Fevereiro & 80 & 3 & 420 \\
\hline Março & 90 & 2 & 405 \\
\hline Abril & 85 & 1 & 397 \\
\hline Maio & 90 & 1 & 379 \\
\hline Junho & 50 & 2 & 270 \\
\hline Julho & 85 & 1 & 316 \\
\hline
\end{tabular}

*Bdj-Quantidade de bandejas de ovos médios

Elaborado pelos autores

O rendimento total em reais durante os 7 meses parciais mensais variaram de $\mathrm{R} \$ 4.024$ para de produção foi de ( $\mathrm{R} \$ 25.296,00)$, e os rendimentos $\mathrm{R} \$ 2.576$, Tabela 4. 
Tabela 4. Receitas mensais do setor avícola de postura do IFPB-Campus Sousa, para total de 500 animais, julho/2017.

\section{Receitas mensais}

\begin{tabular}{lcccccccc}
\hline Produto & Janeiro & Fevereiro & Março & Abril & Maio & Junho & Julho & Total \\
\hline Ovos (Bd) & $\mathrm{R} \$ 3.880$ & $\mathrm{R} \$ 4.024$ & $\mathrm{R} \$ 3.976$ & $\mathrm{R} \$ 3.864$ & $\mathrm{R} \$ 3.760$ & $\mathrm{R} \$ 2.576$ & $\mathrm{R} \$ 3.216$ & $\mathrm{R} \$ 25.296$ \\
\hline
\end{tabular}

*Bdj- Bandeja

Elaborado pelos autores

Com relação ao lucro obtido na atividade, foi constatado que nos meses de janeiro a abril foi considerado muito baixo, com valores respectivamente de $\mathrm{R} \$ 55, \mathrm{R} \$ 199, \mathrm{R} \$ 151$ e $\mathrm{R} \$ 39$ (tabela 5), pois os produtos eram mais destinados ao consumo pelos alunos. Innocentini (2009) encontra resultados bastante diferente da realidade, no sistema de criação de frangos para corte, apresenta um lucro de $(\mathrm{R} \$ 108.273,57)$, isto se da porque a atividade é voltada primordialmente para a larga produção. Os demais meses o lucro foi negativo mostrando que a produção foi bem baixa com relação aos custos de produção elevados.

Contudo é possível destacar que os custos são bem relevantes em referência a produtividade, pois as receitas são bem significativas e cobrem os custos, obtendo um lucro muito bom em muitos dos meses. Porém vale ressaltar que outros meses se obteve lucro negativo pois se tratando de uma instituição educacional, a produção é mais voltada para atender as demandas internas de refeições e o lucro com o excedente destinado a compra de materiais.

Tabela 5. Produtividade mensal do setor avícola de postura do IFPB-Campus Sousa, para total de 500 animais, julho/2017

\section{Lucratividade}

\begin{tabular}{llllllll}
\hline Meses & Janeiro & Fevereiro & Março & Abril & Maio & Junho & Julho \\
\hline $\begin{array}{l}\text { Receitas mensais } \\
\text {-Ovos (Bd) }\end{array}$ & $\mathrm{R} \$ 3.880$ & $\mathrm{R} \$ 4.024$ & $\mathrm{R} \$ 3.976$ & $\mathrm{R} \$ 3.864$ & $\mathrm{R} \$ 3.760$ & $\mathrm{R} \$ 2.576$ & $\mathrm{R} \$ 3.216$ \\
\hline Custos mensais & $\mathrm{R} \$ 3.825$ & $\mathrm{R} \$ 3.825$ & $\mathrm{R} \$ 3.825$ & $\mathrm{R} \$ 3.825$ & $\mathrm{R} \$ 3.825$ & $\mathrm{R} \$ 3.825$ & $\mathrm{R} \$ 3.825$ \\
\hline Lucro & $\mathrm{R} \$ 55$ & $\mathrm{R} \$ 199$ & $\mathrm{R} \$ 151$ & $\mathrm{R} \$ 39$ & $-\mathrm{R} \$ 65$ & $-\mathrm{R} \$ 1.249$ & $-\mathrm{R} \$ 609$
\end{tabular}

Elaborado pelos autores

De acordo com o cálculo da relação custo benefício para a soma de todas as receitas mensais dividido pela soma dos custos mensais, a relação ainda se mostrou positiva com um valor de $R \$ 0,94$ centavos.

Tabela 6. Relação custo benefício do setor avícola de postura do IFPB-Campus Sousa, durante os meses de janeiro a julho de 2018 para total de 500 animais, julho2017.
Relação $\sum \mathbf{R i} / \sum \mathbf{C i}$
$R \$ 25.296 / R \$ 26.775$
$\mathbf{R} \$ \mathbf{0 , 9 4}$
$\mathrm{B} / \mathrm{C}$

\section{CONCLUSÕES}

Diante do que foi estudado observa-se que existem variações de acordo com a demanda apresentada pela instituição uma vez que o funcionamento do setor esta voltado para as práticas estudantis dos alunos que fazem cursos técnicos e superiores, mas mesmo assim se mostra uma atividade de rentabilidade positiva.

$\mathrm{O}$ rendimento total em reais durante os sete meses de produção foi de ( $\mathrm{R} \$ 25.296,00)$, e os rendimentos parciais em reais para tesouraria, agroindústria e refeitório foram respectivamente $(\mathrm{R} \$ 21.376,00)$ e $(\mathrm{R} \$ 3.920,00)$, assim chegamos a conclusão de que a avaliação é positiva e que a criação de aves para postura é rentável e quando associada a outras atividades agropecuárias com manejo agroecológico poderá promover melhor lucratividade ao produtor rural. 


\section{REFERÊNCIAS}

ALBINO, L. F. T. Frango de corte: manual prático de manejo e produção. Viçosa: Aprenda Fácil, 1998. 72p.

ANGELO, J. C. Setor de avicultura em crescimento no Brasil. Portal do Agronegócio. 2010. Disponível em: $<$ http://www.portaldoagronegocio.com.br/artigo/setor-deavicultura-em-crescimento-no-brasil>. Acesso em 29 de Agosto de 2017.

COSTA, M. V.; JÚNIOR, W. L. C.; FILHO, F. B. B. Custo de produção na avicultura alternativa do Distrito federal. IN: XLIII CONGRESSO DA SOBER. $2005 . \quad$ Disponível em: <http://docplayer.com.br/21501491-custo-de producaona-aviculturaalternativa-do-distrito-federal >. Acessado em 01 de agosto de 2017.

GIROTTO, A. F. Custos de produção de ovos. Embrapa Suínos e Aves, 2008, 45p.

HOFFMANN, R.; ENGLER, J.J. de C.; SERRANO, O.; THAME, A.C.M.; NEVES, E.M. Administração da empresa agrícola. 3. ed. São Paulo, SP: Livraria Pioneira Editora, 1981. 181p.
INNOCENTINI, R.C.P. Análise dos custos de produção de frangos de corte nos sistemas integrado e independente. Veterinária Notícias, Uberlândia, v.15. n.2, 2009.

MARTINS, Eliseu. Contabilidade de Custos. 8. ed. São Paulo: Atlas, 2001.

NAYLOR, T.H.; VERNON, J.M. Economia de la empresa. Buenos Aires. Centro Regional de Ayuda Técnica. Amorrortu Ed., 1973. 506 p.

NÓBREGA, E. P., et al. Desenvolvimento inicial de mudas de goiabeira irrigadas com diferentes tipos de água. Revista de Agroecologia no Semiárido, v. 1, n. 2, p. 01-09, 2018.

SCHWARTZ, F. F., GAMEIRO, A. H. Análise de custobenefício de sistema de produção de ovos em gaiolas (em bateria) e sem gaiolas (caipira) nos estados de São Paulo e Paraná. Empreendedorismo, Gestão e Negócios, v. 6, n. 6, 2017, p. 132-147

YIN, R. K. Case study research: Design and methods. Thousand Oaks, CA: SAGE Publications, 2002. 